\title{
QUANTITATIVE ANALYSIS OF THE OPERATIONAL PERFORMANCE OF THE SELECTED NON-LIFE INSURANCE COMPANIES IN THE INSURANCE MARKET OF REPUBLIC OF NORTH MACEDONIA
}

\author{
Angela Blazheska \\ Faculty of Economics - Skopje, Ss Cyril and Methodius University \\ blazheska.angela@,gmail.com \\ Igor Ivanovski \\ Faculty of Economics - Skopje, Ss Cyril and Methodius University \\ igor.ivanovski@eccf.ukim.edu.mk
}

\begin{abstract}
The aim of this paper is to analyze the operational performance of the 5 dominant companies on the non-life insurance market in Republic of North Macedonia. As input in the analysis, the quarterly data for the 2009-2019 period is included for the key indicators such as the gross written premium (GWP), the gross liquidated damages, the number of insurance contracts and settled claims as well as the operating costs of the companies. These variables are observed through OLS (Ordinary Least Squares) regression analysis and VAR (Vector Autoregressive) model which demonstrates the dependence of the GWP to the rest of the indicators and their responsiveness to shocks. The findings of the study offers valuable insight and opportunities for short term recommendations and further exploration.

The companies are missing the sustainability and viability of their management models and define the "shortcism" as more important for the market and operational performance. In these regard, the business models must introduce contemporary and comprehensive tools and techniques, dominantly based on IT solutions and adequate HCM changes, for risk identification and actions for lowering the claims ratio and their volume. Moreover, all the companies should evaluate the elements of the operating costs, both for sales as well as of the administrative ones, as critical components for the companies' profitability. Very importantly, significant changes at the ALM models and higher rate of returns should inevitably create additional advantage for dynamic and sustainable models for consumer acquisition and new products and services development.
\end{abstract}

Keywords: operational performance, non-life insurance, GWP.

JEL classification: $C 32, G 22, C 53$

\section{INTRODUCTION}

Maximization of the utility function and the profits is the ultimate purpose of the management and the equityholders of every private company. One of the most researched topics in the literature regarding the financial and insurance markets is the companies' profitability analysis and the determinants that lead to successful and sustainable business strategy. It is therefore crucial for the management to progress towards enhancement in the operative efficiency, advancement in the products and services and the channels for distribuions, technology and human capital developments as main pillars for achieving the expected financial results. This affects the companies' competitiveness and market share position as well as the overall market developments.

The aim of this paper is to analyze the operational efficiency of the non-life insurance companies on the North Macedonian insurance market. Focus is set to the gross written premium (GWP) as a main indicator of performance and dominant source of income from the 
core activities, for which several variables are assigned to determine the extent to which they explain the variations in the profitability. Among these are the gross liquidated damages, the number of insurance contracts and claims settled as well as the operative costs of the companies. The study is conducted for the 5 dominant players in the non-life insurance business.

Initially an overview of the consulted literature and the overall market developments is presented, followed by description of the methodology of the analysis and the model implemented. The results for the companies studied are presented consequently. Finally, the main findings are summarized in the concluding part with further recommendation for the stakeholders and interested parties.

\section{LITERATURE OVERVIEW}

Crucial aspect of the prospective market developments and the companies' growth is their operative success. Main indicator of the business performance and the profitability of providing the insurance services is the GWP. Therefore, the determination of the factors that have influence on it is of high importance. There are varios papers that focus on performance analysis of the insurance companies on the market and employ models that incorporate the effects of microeconomic and macroeconomic factors that might affect its growth trends.

Usually, most of the studies include the financial leverage and liquidity, the ROA/ROI coefficients, companies' size, and various internal factors such as human capital and technological improvements and examine the effects on the profitability through the GWP, leading to the conclusion of needed sustainability of the business models for enhancement in the performance. (Almajali et al., 2012; Charumathi, 2012) In some developing countries where the market still has relatively small contribution to the overall financial system activity, indicators such as the technical provisions, solvency and loss coefficient i.e. the ratio of the liquidated claims in the total revenue, explain the changes in the companies' profitability. (Mehari, Aemiro, 2013; Hailegebreal, 2016; Adams, Buckle, 2003; Ahmed et al., 2010; Pervan et al., 2012)

In some cases the companies' profitability is negatively correlated with the increase in the GWP which is explained with higher risk for proper estimation of the costs related to the liquidation of the claims, leading to higher levels of technical reserves. (Burcă, Bătrînca, 2014) Furthermore, this reflects into higher loss ratio which eventually negatively affects the stability and sustainability of the companies. However, except for the costs for claims liquidation also the operative costs of the companies for networking, marketing and advertisements, sales agents and provisions seriously affect their position and competitiveness on the market. Consequently, the companies need to focus on discipline in concluding insurance contracts and to have higher control over the costs for liquidation of the damages in order to achieve better business results. (Venkateswarlu, Bhishma Rao, 2016) Some studies observed the impact of the macroeconomic and microeconomic indicators to the insurance companies' performance in the process of EU integration and found that the cost efficiency and profitability improved owing to the inflow of foreign capital, the increase in GWP and decline in the operating costs, as well as imrpovements in the economic activity as measured with the GDP indicator. (Kozak, 2011)

In this study the companies' performance is measured in a setting where the market is still developing and with a significantly lower contribution of the total GWP in the economic activity as measured with the GDP indicator, compared to the regional markets. Through modelling of the gross liquidated damages, the number of insurance contracts and liquidated 
claims, as well as the operating costs as determinants that have potential significant influence on the GWP, the success of the companies in achieving the goal of enhanced business performance and long term stability is aimed to be confirmed.

\section{ANALYSIS OF THE NON-LIFE INSURANCE MARKET}

The overall insurance industry in Republic of North Macedonia is a developing and growing market, with prevalent domination of the non-life insurance. The market witnessed rapid growth over the last decade, that is associated with several dominant factors such as: (i) establishment of new foreign owned companies, at both market segments, life and non-life; (ii) introduction of adequate regulation and supervision, still under the Solvency I regime and (iii) increase of the demand, due to the offer of new insurance products and development of vast intermediary network. Despite those facts, the overall industry capacity and development remains low compared to the growing and developed markets with long term ration od 1,5\% insurance penetration (ISA, 2020) and dominant position of non-life market that accounts to $83 \%$ of the GWP by 2019 (ISA, 2020).

Furthermore, when analyzing the market, we should note the most significant fact related to the market evolution and its inherent risk, namely, almost half of the non-life insurance activity and GWP is dedicated to the single class of auto insurance, as the mandatory insurance, heavily administratively regulated and still lagging the immanent market model of liberalization and free competition. In concrete, the proportion of the auto insurance GWP by 2019 resulted at 53 $\%$ of the non-life GWP, thus remaining the main catalyst and additionally inherent risk based insurance within the industry.

The non-life industry is consisted of 11 companies, with dominant foreign ownership. The market is low concentrated, defined by both Herfindal and CR5 indices and is highly competitive. The relative growth of the non-life market, that is main focus of his paper, even though lower than the previous years, remains still high with rate of 9,43\% (18/17) and 5,99\% $(19 / 18)$, while the semiannual growth rate at the crisis pandemic year is set up to the negative decline of $10 \%$ in comparison to the first half of 2019 , as an expected indicator in relation to the countries and regional lockdown's and close of the economic activities. In addition the main engine of the non-life market growth is related to the growth of the auto insurance growth that constantly appears above $5 \%$ annually.

However, we should analyses the non-life companies growth and in particular the profitability in contextual manner and in relation to the factors of: (i) their non-insurance activities, i.e. investments and (ii) their core business costs, measured primarily by the acquisition costs and the claims costs, determined by the combined ratio.

In this context, the non-life insurance companies are struggling to improve their activities for acquiring higher investment returns as key component for adjusting the financial results and achieving higher profitability, while the competitive pressure determines higher acquisition costs, both for direct and especially for the intermediary sales. The later, represent one of the key milestones for the national non-life market and represent the long term burden for the company's profitability, prevailing at the dominant auto insurance class. In general, the growth of the industry is not consequently followed by the development and improvement of the basic and advanced managerial models for core and non-core insurance business. Heavy reliance to the single mandatory class of auto insurance, less diversified insurance supply and low focus on creating new demand, determines severe competition among the companies and managerial approach for retaining the market share by "sales at any cost" that determines the high level of costs. Inherent risks of the industry are additionally linked to the limited management of claims 
settlement and poor, missing or non-effective strategies for lowering the risk throughout use of the IT mechanisms and tools, as well as by more diversified risk portfolios. In these regard, the combined ratios are seldom above 100, thus endangering severely companies' prospects for sustainable profitability. Namely, the net combined ratios of the non-life market, excluding the effects of the reinsurance, are calculated at the critical level of 103,96\% (2019) and is raising from the level of $99,5 \%$ (2018). Moreover, the internal composition of the ratio for 2019 is set by $52,50 \%$ of claims coefficient and $51,46 \%$ of premium acquisition coefficient (ISA, 2020). The later, defines the critical importance of the need for significant changes of the non-life industry.

As previously stated, the financial results of the non-life companies are worsening, due additionally to the limited and declining results at the ALM policies. Namely, the 2019 year resulted with critical results of overall industry loss, thus the losses of four companies was higher than the low surplus of the remaining 7 companies. These trends are worrying and should be matter of urgent reshape of doing the insurance business. Additionally, the non-life companies' actions for investments resulted in declining rate of $1,42 \%$ of ROI that is almost $100 \%$ drop compared to the $2,46 \%$ of ROI for 2018 at the overall non-life market level. Consequently, the ROA rate for the non-life industry was negative at the level of $-0,8 \%$ (2019) that is significant decline from the level of $1,8 \%$ of ROA for 2018. In relation to that, the overall operational performance of the companies defines the crucial component of the company's profitability, as the investment activities are limited, less diversified and define the spill-over effect to the limited profitability of the sector. We should not that the main non-life companies investment instruments are the bank deposits and state bond, representing over $88 \%$ of the total investments of the technical reserves.

While the overall insurance industry solvency is stable and the solvency margin is 3,9 times higher than the minimal level, mainly due to the increased regulatory and supervisory measures and previous companies' capital reserves, yet, the lack of higher profitability, as a result of the limited operational performance of the companies deprives the more intense and sustainable development of the industry itself.

In conclusion to this part of the paper, the need of empirical analyses for determining the operational management of the companies, and the particular influence of the selected variables defines the importance for creating necessary conclusions for companies managerial and business mode changes as key for their future internal and specific transformation and market development.

\section{METHODOLOGY AND RESULTS}

For the purpose of detecting how the companies' main operational parameters affect the performance, the model includes several variables such as the number of insurance contracts, the number and the gross liquidated claims as well as the operative costs and provisions which arise from the process of selling the insurance policies. These parameters are observed through OLS (Ordinary Least Squares) regression analysis, for which the database consists of the quarterly data for each variable for the 2009-2019 period including the 5 dominant companies which constitute around $60 \%$ of the Macedonian non-life insurance market. The data is obtained from the quarterly reports of the North Macedonian Insurance Supervision Agency with extrapolation, since originaly they are aggregated on quarterly level, and monthly data is not available. For the purpose of conducting regression analysis, the time series are tested for stationarity with the Augmented Dickey-Fuller test. Non-stationary time-series are prone to shocks and their variance grows exponentially as time progresses. Therefore it is crucial that 
the variables are stationary and that the effects of potential shocks diminish quickly as the time horizon expands. Therefore, the series which are non-stationary are differentiated through generating logarithmic sequences of the original data. ${ }^{1}$

Consequently, the regression analysis is performed where the GWP (Gross Written Premium) variable is analyzed as dependent from the rest of the indicators. Or represented mathematically:

$$
y t=\beta_{1}+\beta_{2} x_{2} t+\beta_{3} x_{3} t+\cdots+\beta_{k} x_{k} t+u t, t=1,2, \ldots, T .,
$$

, where $x_{1} t, x_{2} t, \ldots, x_{k} t$ stands for the independent variables, and $\beta_{1}, \beta_{2}, \ldots, \beta_{k}$ are parameters that quantify the magnitude of the effect which each of the independent variables imposes on the GWP as dependent. Through this, for each independent variable under the null hypothesis we test whether there is no significant influence on the dependent variable:

$$
\begin{gathered}
\mathrm{H}_{0}: \boldsymbol{\beta}_{1}=\boldsymbol{\beta}_{2}=\cdots=\beta_{k}=0 \\
\mathrm{H}_{1}: \text { At least one of } \beta_{1}=\beta_{2}=\cdots=\beta_{k} \neq 0
\end{gathered}
$$

Rejecting the null hypothesis supports the hypothesis that at least one of the predictor variables has a significant linear relationship with the response variable. At the significance level of $5 \%$, if the p-value of the F-test statistics is lower than 0.05, then the zero hypothesis is rejected. Since the series are differentiated and the values are logarithmic, the coefficients of the regression represent the elasticity of the dependent variable in percentage change of the independent factors.

Furthermore, VAR (Vector Autoregressive) analysis is deployed to observe the impulse response and variance decomposition aimed to detect how the variables are correlated and thus respond to possible shocks. All the variables in the VAR models are treated as endogenous (independent) so that the interconnections between them are examined and the system includes 2 lags according to the Schwartz criteria. The impulse response demonstrates how the distortions in one of the variables influences the stability of the rest, whether the shocks are positive or negative and to what extent their impact persist during the period observed. If the shocks decline promptly then it can be assumed that the system is stable and the shocks do not cause serious deviations in the rest of the determinants.

Finally, the variance decomposition is suitable for observing the proportion of the deviations which are explained by the variance of the rest of the variables in the system. This concept is applied to each of the analyzed companies separately and the results are presented subsequently.

\subsection{Performance analysis of 'Triglav Insurance'}

Triglav Insurance has $16,3 \%$ market share according to the 2019 non-life insurance market analysis, observed from the aspect of the total GWP contribution, which makes the company a market leader. Over the course of 10 years the company achieved average quarterly growth of $2 \%$ in the total GWP followed by $5 \%$ increase in the number and gross value of liquidated claims as well as the number of insurance contracts concluded. The operating costs grew with average quarterly rate of $6 \%$.

\footnotetext{
${ }^{1}$ Cheung, Y., W., and Lai, K., S. (1995) Lag Order and Critical Values of a Modified Dickey-Fuller Test, Oxford Bulletin of Economics and Statistics, Vol. 57, pp. 411-418
} 
Table 1. OLS Regression Analysis for Triglav Insurance

\begin{tabular}{|c|c|c|c|c|}
\hline \multicolumn{5}{|c|}{ DGWP $=$ f(DGLD,DNCL,DNIC,DOC) } \\
\hline \multirow{2}{*}{ Variable } & \multirow{2}{*}{ Coefficient } & Stand. Eror & t-Statistic & \multirow{2}{*}{ Probability } \\
\hline Constant & -0.00355 & 0.022691 & -0.1564 & 0.8765 \\
\hline DGLD & -0.27169 & 0.101037 & -2.68904 & 0.0106 \\
\hline DNCL & -0.16469 & 0.116828 & -1.40965 & 0.1668 \\
\hline DNIC & 0.229667 & 0.07647 & 3.003364 & 0.0047 \\
\hline DOC & 0.160274 & 0.116326 & 1.377799 & 0.1763 \\
\hline \multicolumn{4}{|c|}{$\mathrm{R}^{2}=46 \%$} & \\
\hline
\end{tabular}

Source: ISA quarterly reports, authors' estimations

From the OLS regression analysis it can be noted that $46 \%$ of the total variations of the GWP variable is explained with the factors indicated in the model. At the $5 \%$ level of significance it is confirmed that the gross liquidated claims have negative correlation with the dependent variable, implying that the increase in the value of covered damages leads do decline in the total GWP of the company. On the other hand, the increase in the number of insurance contracts leads to increase in the GWP, with highly significant connection even at $1 \%$ level.

Graph 1. Impulse Response

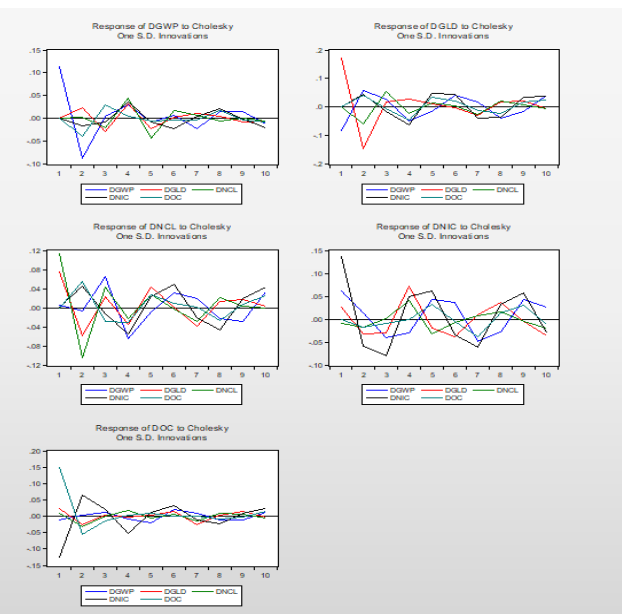

Graph 2. Variance Decomposition

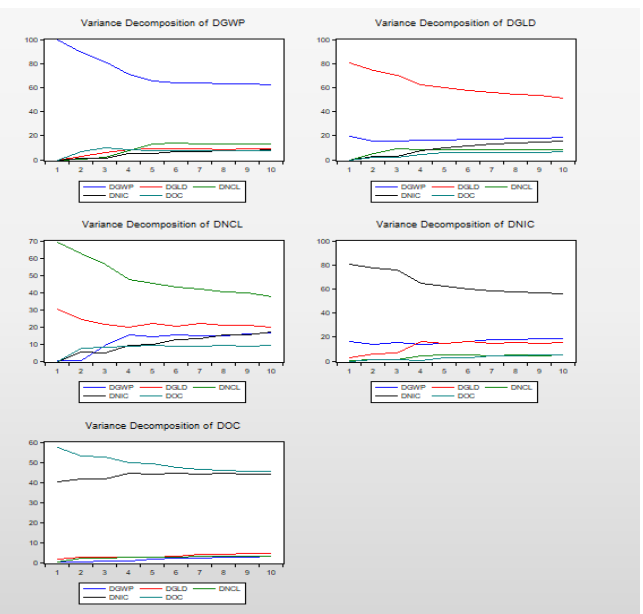

Source: Authors' estimation

When the GWP is analysed, the shocks immane nt to the number of insurance contracts cause fluctuations in the forecasted period, whereas the rest of the variables do not have significant influence on the dependent, since they mark decline after their highest magnitude - from the $4^{\text {th }}$ period onwards. On the contrary, the gross liquidated damages are prone to shocks which are more persistent and are influenced by the fluctuations in the number of insurance contracts and the GWP. More serious distorsions are evident for the number of claims settled where the shocks that affect the rest of the determinants have impact on the stability of the system, even though the standard errors are in the +/- 0.04 interval. This holds also true for the number of insurance contracts where there are shocks caused from the changes in the gross liquidated claims and operating costs even though they decline more promptly than the GWP which follows the path of the number of insurance contracts but with a delay and higher persistence in the observed period. (Graph 1) 40\% of the variance of the total GWP of the company can be explained with the variations in the rest of the components which contribute equally with $10 \%$ each. The variance of the gross liquidated damages declines at the expense of the increase in the variations of the number of insurance contracts, and vice versa. On the other hand, the fluctuations in the GWP, gross liquidated damages and the number of insurance contracts account for $60 \%$ of the variance of the number of claims settled. Finally, the variance of the 
operating costs can be predominantly explained with the distorsions in the number of insurance contracts. (Graph 2)

\subsection{Performance analysis of 'Eurolink Insurance'}

Eurolink Insurance marked 11,6\% market share in 2019 as a second dominant company on the non-life insurance market observed from the aspect of the total GWP contribution. In the 20092019 period the company achieved average quarterly growth of 7\% in the total GWP and the number of claims settled. These indicators are followed with $4 \%$ increase in the gross liquidated claims, $10 \%$ average quarterly growth of the number of insurance contracts and $20 \%$ in the operating costs.

Table 2. OLS Regression Analysis for Eurolink Insurance

\begin{tabular}{|c|c|c|c|c|}
\hline \multicolumn{5}{|c|}{ DGWP $=\mathbf{f}$ (DGLD,DNCL,DNIC,DOC) } \\
\hline \multirow{2}{*}{ Variable } & Coefficient & Stand. Eror & t-Statistic & Probability \\
\hline Constant & 0.003696 & 0.043094 & 0.085776 & 0.9321 \\
\hline DGLD & 0.497547 & 0.186412 & 2.669076 & 0.0111 \\
\hline DNCL & -0.19308 & 0.154723 & -1.24791 & 0.2197 \\
\hline DNIC & 0.013143 & 0.080326 & 0.163625 & 0.8709 \\
\hline DOC & 0.235118 & 0.081276 & 2.892816 & 0.0063 \\
\hline \multicolumn{5}{|l|}{$\mathrm{R}^{2}=31 \%$} \\
\hline
\end{tabular}

Source: ISA quarterly reports, authors' estimation

The model estimations demonstrate positive correlation between the GWP and the gross liquidated damages implying that the increase in the amount paid for claim settelment increases the gross premium earned, and this relationship is evident at 5\% level of significance. At the significance level of $1 \%$, it can be concluded that there is positive impact of the increase in the operating cost to the dependent variable. The independent determinants in the model explain $31 \%$ of the changes in the GWP of the company.

For the GWP the fluctuations are stabilize after the $4^{\text {th }}$ period with slightly higher influence of the changes in the gross liquidated damages. This also holds true for the rest of the variables with the exception of the number of insurance contracts which is highly dependent on the distorsions that affect the number and amount of liquidated claims, even though the effect declines as time progresses. (Graph 3) Around 40\% of the GWP variance can be explained with the variations in the gross settled damages and vice versa. The latter are also dependent on the variance of the operating costs. As the time horizon expands, the shocks that are immanent for the numer of claims settled decline at the expense of the gross liquidated damages. Fluctuations in the number of covered claims explain half of the variance in the number of insurance contracts. Finally, the distorsions in the rest of the determinants explain $60 \%$ of the total variance of the operating costs. (Graph 4) 
Graph 3. Impulse Response

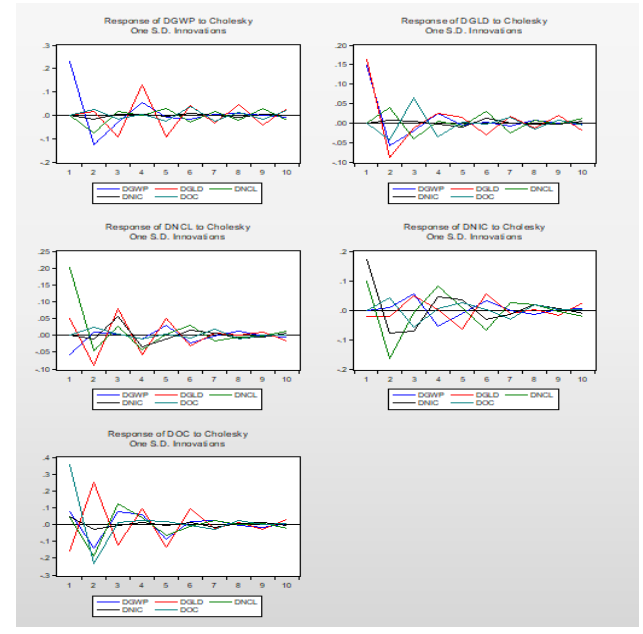

Graph 4. Variance Decomposition

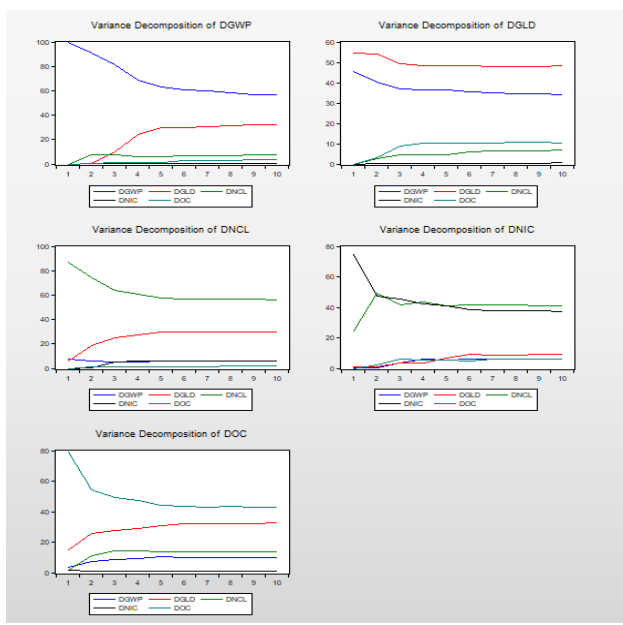

Source: Authors' estimation

\subsection{Performance analysis of 'Insurance Macedonia'}

Insurance Macedonia has 10,6\% market share according to the 2019 non-life insurance market analysis, observed from the aspect of the total GWP contribution. According to the performance observations in the analyzed period, the company marked $3 \%$ average quarterly growth of the GWP, followed by $2 \%$ growth in the number of insurance contracts and the gross covered damages. A $5 \%$ average quarterly increase is noted for the number of liquidated claims, whereas the operating costs grew with $7 \%$.

Table 3. OLS Regression Analysis for Insurance Macedonia

\begin{tabular}{|c|c|c|c|c|}
\hline \multicolumn{5}{|c|}{ DGWP $=\mathbf{f}(\mathbf{D N C L}, \mathbf{D G L D}, \mathbf{D O C})$} \\
\hline Variable & Coefficient & Stand. Eror & t-Statistic & Probability \\
\hline Constant & -0.012239 & 0.040011 & -0.305889 & 0.7613 \\
\hline DNCL & -0.225592 & 0.13 & -1.735327 & 0.0906 \\
\hline DGLD & -0.103276 & 0.149138 & -0.692483 & 0.4927 \\
\hline DOC & 0.030249 & 0.112853 & 0.268039 & 0.7901 \\
\hline \multicolumn{5}{|c}{} \\
\hline
\end{tabular}

Source: ISA quarterly reports, authors' estimation

Compared to the rest of the companies, here the variable number of insurance contracts is excluded from the model for causing high insignificance in the rest of the coefficients and adding none to the coefficient of determination, which even after these modifications is still at very low level of $8 \%$ implying that the variables in the model do not explain the dependent significantly. It can be concluded that only the number of claims liquidated are negatively correlated with the dependent meaning that their increase will cause decline in the GWP, but only at $10 \%$ significance level. 
Graph 5. Impulse response

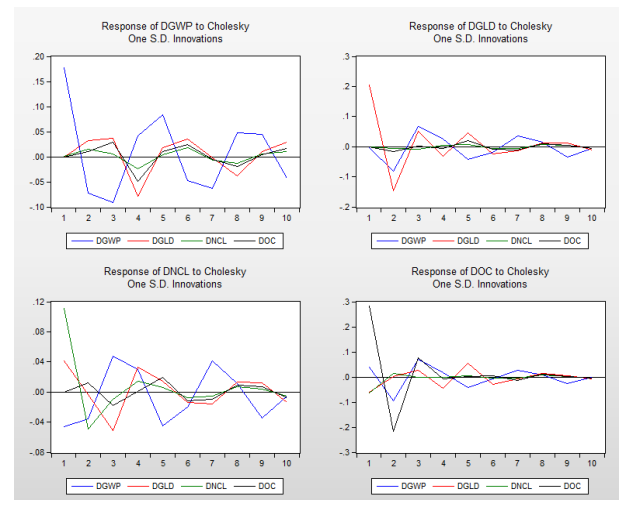

Graph 6. Variance decoposition

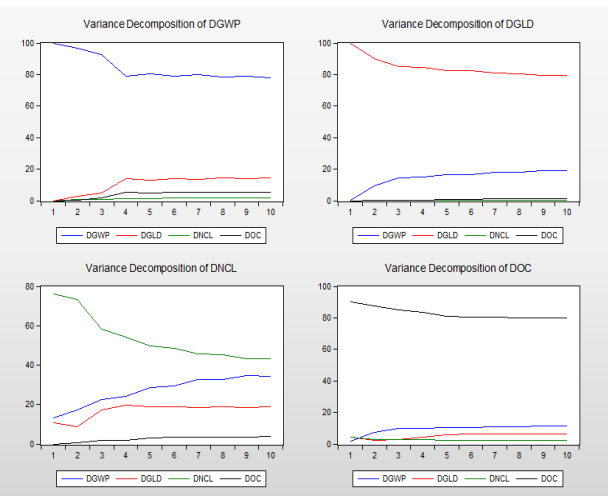

Source: Authors' estimations

Responses to shocks and the interconnection between the determinants are demonstrated on graph 5. For the GWP, gross liquidated damages and the operating costs it is evident that the distorsions caused by the rest of the determinants decline shortly after the $4^{\text {th }}$ period meaning that they do not affect the fluctuations in the variables in question. The only exeption are the number of claims liquidated which are influenced by the distorsions in the GWP and these shock persist for longer time period, even though the standard error width is between $+/-0.04$.

If the variance is decomposed it can be concluded that $20 \%$ of the GWP variance can be explained with the deviations in the gross liquidated claims and vice versa. $80 \%$ of the changes in the gross liquidated damages are due to the fluctuations in the GWP. This also holds true for the number of insurance contracts and the number of liquidated claims. The deviations in the costs are equaly due to the shocks attributed to the variable itself as well as those which are immanent for the GWP, with around 10\% contribution of the fluctuations in the number of contracts as well. Around $60 \%$ of the variance in the number of liquidated claims is attributed to the changes in the amount of paid claims and the GWP which marks increased contribution as time progresses. (Graph 6)

\subsection{Performance analysis of Sava Insurance}

With a 10,3\% market share according to the 2019 non-life insurance market analysis, Sava Insurance takes over the 4th position viewed from the total GWP share indicator perspective. In the ten year period the company achieved $7 \%$ average quarterly GWP growth and $8 \%$ growth in the gross liquidated damages, the number of insurance contracts and the operating costs. These indicators are followed with a 3\% quarterly increase in the number of settled claims.

Table 4. OLS Regression Analysis for Sava Insurance

\begin{tabular}{|c|c|c|c|c|}
\hline \multicolumn{5}{|c|}{ DGWP = f(DGLD,DNCL,DNIC,DOC) } \\
\hline \multirow{2}{*}{ Variable } & Coefficient & Stand. Eror & t-Statistic & \multirow{2}{*}{ Probability } \\
\hline Constant & -0.0047 & 0.04637 & -0.1013 & 0.9198 \\
\hline DGLD & -0.1874 & 0.14303 & -1.3102 & 0.198 \\
\hline DNCL & 0.80954 & 0.33914 & 2.38705 & 0.0221 \\
\hline DNIC & 0.35448 & 0.13332 & 2.6588 & 0.0114 \\
\hline DOC & 0.03616 & 0.15082 & 0.23975 & 0.8118 \\
\hline \multicolumn{4}{|l|}{$\mathrm{R}^{2}=26 \%$} & \\
\hline
\end{tabular}

Source: ISA quarterly reports, authors' estimation 
According to the OLS regression model, only $25 \%$ of the deviations in the GWP can be explained with the independent variables. Both the number of insurance contracts and the number of liquidated claims have positive correlation with the dependent, meaning that the increase of the number of insurance contracts conducted or the number of claims settled affects positively the performance of the company analysed through the GWP indicator.

Graph 7. Impulse response

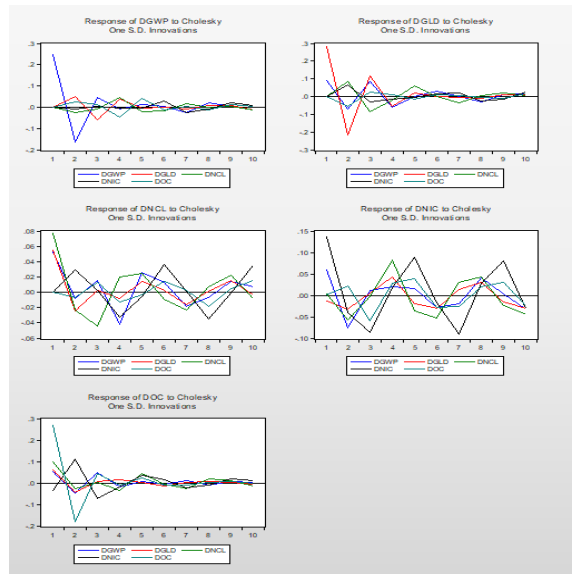

Graph 8. Variance decomposition

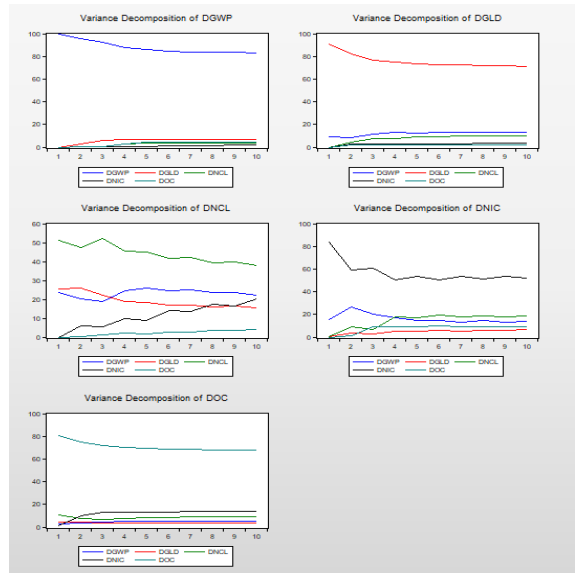

Source: Authors' estimation

The responsiveness of the GWP, the gross liquidated damages and the operating costs to the shocks that impact the rest of the variable is low and the systems stabilize after the $3^{\text {rd }}$ period. (Graph 7). On the contrary, both the number of insurance contracts and the claims settled are interconnected and also dependent on the shocks that are immanent to the GWP and the amount of liquidated damages, even though the range of the standard deviation is between $+/-0.10$ and lower compared to the rest of the variables.

If analysed through the variance perspective only the fluctuations in the gross liquidated damages have more significant impact on the GWP and vice versa. The variance structure of the determinant number of claims settled can be explained with the deviations in the GWP, the amount of liquidated damages and the number of insurance contracts with around $60 \%$. On the other hand, these same variables have $40 \%$ impact on the number of insurance contracts variance. Compared to the rest of the determinants, the variance of the operating costs has only minor influence of the shocks in the number of insurance contracts. (Graph 8)

\subsection{Performance analysis of 'Winner Insurance'}

Winner Insurance has 9,2\% contribution in the total GWP according to the 2019 non-life insurance market analysis. Even though it does not belong to the group of 5 dominant companies on the market, it is included in this analysis as a representative of the non-life companies in the medium segment for which the market contribution is approximately equal and fluctuates as time progresses. The position of Vienna Insurance Group in the CEE market is significant and therefore we believe that it is important that this study elaborates on the factors that lead towards changes in its performance as one of the key players in the domestic insurance market. Observed through the main performance determinants, the company marked $10 \%$ average quarterly GWP growth for the period in question, followed by $6 \%$ increase in the number of liquidated claims and $8 \%$ in the number of insurance contracts. An average quarterly increase of $20 \%$ is noted for the gross liquidated damages, whereas the operating costs grew with $27 \%$. 
Table 5. OLS Regression analysis for Winner Insurance

\begin{tabular}{|c|c|c|c|c|}
\hline \multicolumn{5}{|c|}{ DGWP = f(DGLD,DNCL,DNIC,DOC) } \\
\hline \multirow{2}{*}{ Variable } & Coefficient & Stand. Eror & t-Statistic & Probability \\
\hline Constant & 0.05038 & 0.04578 & 1.10051 & 0.278 \\
\hline DGLD & -0.1569 & 0.09496 & -1.6519 & 0.1068 \\
\hline DNCL & -0.8427 & 0.19131 & -4.4051 & 0.0001 \\
\hline DNIC & 0.12831 & 0.1671 & 0.76787 & 0.4473 \\
\hline DOC & -0.0144 & 0.07627 & -0.1893 & 0.8509 \\
\hline \multicolumn{4}{|l|}{$\mathrm{R}^{2}=40 \%$} \\
\hline
\end{tabular}

Source: ISA quarterly reports, authors' estimation

It can be stated that the independent variables determine $40 \%$ of the changes in the GWP, according to the OLS regression estimates. Solely the relationship between the number of claims settled and the GWP is highly significant at 1\% significance level, implying that the increase in the total number of covered claims would result in increase in the gross written premium. At 10\% significance level, it can be noted that the gross liquidated damages also have negative correlation with the dependent variable.

\section{Graph 9. Impulse response}

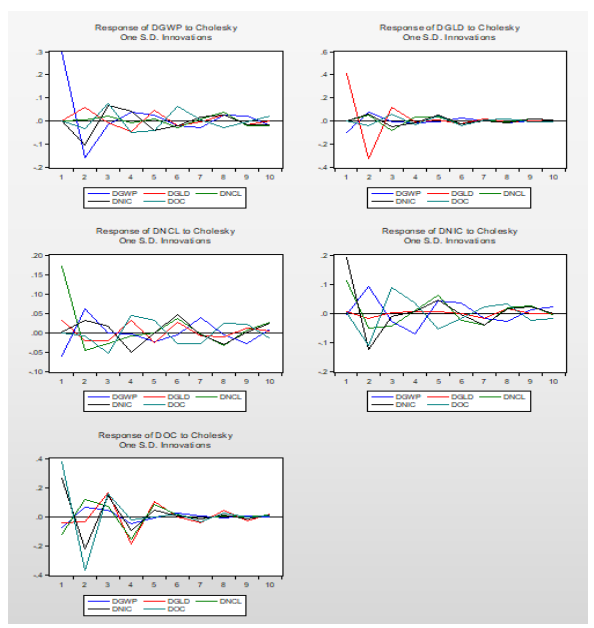

\section{Graph 10. Variance decomposition}

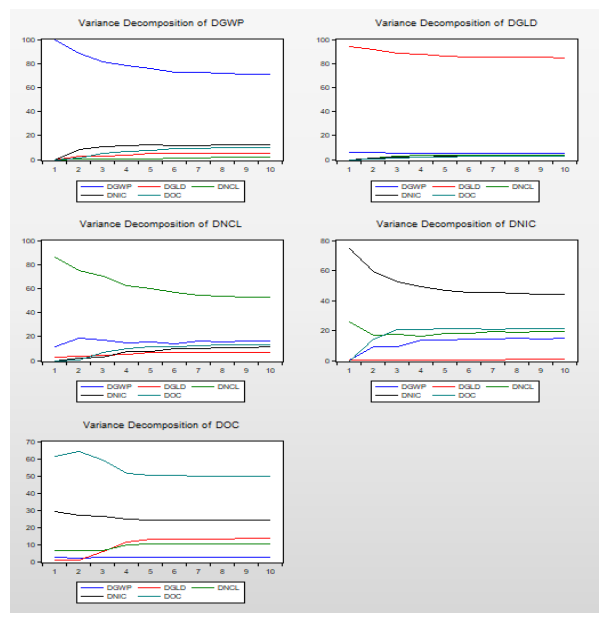

Source: Authors' estimations

Whereas for the gross liquidated damages the fluctuations are stable around zero, the GWP has higher responsiveness to shocks caused by changes in the operating costs and the value of settled claims. (Graph 9) The variations in the number of liquidated claims are affected by the changes in all of the variables and they persist for a longer time period even though the interval of the standard deviations is low at $+/-0.05$. Higher intensity of deviations is evident for the number of insurance contracts owning to the shocks immanent for the operating costs followed by the GWP. For the operating costs, the shocks are evident until the $4^{\text {th }}$ period after which the system stabilizes around zero. Approximately $20 \%$ of the variations in the GWP can be explained with the variations in the number of insurance contracts and the operating costs. On the other hand, the GWP has influence on the variance of the gross liquidated claims. The shocks to the rest of the variables in the system account for $40 \%$ of the changes in the number of liquidated claims and $60 \%$ of the fluctuations in the number of insurance contracts. Finally, the operating costs are predominantly influenced by the changes in the number of insurance contacts with around $30 \%$ of the total variance. (Graph 10) 


\section{CONCLUSION}

The operational performance of the insurance companies is highly dependable to the companies' core business activities as well as to the inherent companies' risks and general market conditions. The increasing competitive pressure at the insurance markets and declining investment revenues due to the low interest rates, imposes the significance of improved managerial models and changes of the business models for retaining and improving the companies' market position and competitiveness.

The results from the OLS regression demonstrate that in each of the cases, at least one of the independent variables has significant impact on the dependent variable, the GWP, which leads to rejection of the null hypothesis in favor of the alternative. In general, these variables are the number of claims and liquidated damages. There is evident positive influence of increase in the number of contracts to the gross revenue of the companies, however accompanied with higher costs for liquidating the claims which negatively impacts the GWP, leading to eventual inefficiency in the core operative processes and depriving further their profitability.

The findings are in line with the expectations as well as with the results from vast studies that are focusing of the determinants of operational performance of the insurance companies. The national non-life insurance market, that is highly competitive and limited in depth and maturity, is heavily dependent on limited number of insurance classes and products as the prevalence of the auto insurance remains high. In addition, the high level of combined ratio and low rates of ROA and ROI again determines the limited profitability of the companies. In that context, the volatility of the observed variables confirmed the influence to the GWP as it is highly linked to the companies' managerial concepts for retaining and acquiring new consumers. Primarily, we can determine the companies' orientation for acquiring new consumers regardless of the high operating costs for the process and its influence to the profitability. Secondly, the role of the claim management could be understood as "swinging" instrument either for improving the most critical process for the industry and the consumer satisfaction or for the balance sheets improvements on a short run that causes lower retention rates and increase of the reputational risks.

The companies are missing the sustainability and viability of their management models and define the "shortcism" as more important for the market and operational performance. In these regard, the business models must introduce contemporary and comprehensive tools and techniques, dominantly based on IT solutions and adequate HCM changes, for risk identification and actions for lowering the claims ratio and their volume. Moreover, all the companies should evaluate the elements of the operating costs, both for sales as well as of the administrative ones, as critical components for the companies' profitability. Very importantly, significant changes at the ALM models and higher rate of returns should inevitably create additional advantage for dynamic and sustainable models for consumer acquisition and new products and services development.

Finally, the observed period is linked to the relatively high rates of non-life insurance activity and yet, limited companies' profitability. The growth of the GWP is linked to the significant variations of the operating, acquisition and claims/damages costs. In this relation, the companies as part of the non-life market are below the internal and external (market) potential and transformational changes are expected. The authors would closely examine the recent industry developments, in particular in light of the crisis caused by the Pandemic, and would continue work on the evidence for operational performance of the companies in correlation to the analyzed factors, as well as the analyses would be broaden with additional inherent companies and market factors. 


\section{REFERENCES}

Adams, M. and Buckle, M. (2003). The Determinants of Corporate Financial Performance in the Bermuda Insurance Market, Applied Financial Economics, Routledge, 13, 133-143. EBMS Working Paper EBMS/2000/12 (ISSN: 1470-2398).

Ahmed, N., Ahmed, Z. and Ahmed, I. (2010). Determinants of Performance: A Case of Life Insurance Sector of Pakistan, European Journal of Economics, Finance and Administrative Sciences, Issue 24, pp. 7-12

Almajali, A. Y., Alamro, A. S. and Al-Soub, Y. Z. (2012). Factors Affecting the Financial Performance of Jordanian Insurance Companies Listed at Amman Stock Exchange. Journal of Management Research, ISSN 1941-899X, Vol. 4, No. 2.

Burcă, A. \& Bătrînca, G. (2014). The Determinants of Financial Performance in the Romanian Insurance Market, International Journal of Academic Research in Accounting, Finance and Management Sciences, Vol. 4, pp. 299-308

Charumathi, B. (2012). On the Determinants of Profitability of Indian Life Insurers - An Empirical Study, Proceedings of the World Congress on Engineering, Vol. 1 WCE 2012, July 4-6, 2012, London, UK, ISBN: 978-988-19251-3-8.

Hailegebreal, D. (2016). Macroeconomic and Firm Specific Determinants of Profitability of Insurance Industry in Ethiopia, Global Journal of Management and Business Research: C Finance, Vol. 16, pp. 26-36

Insurance Supervision Agency, (2009-2020), Reports on the insurance market, ISA, Skopje, R.N. Macedonia

Kozak, S. (2011). Determinants of Profitability of Non-Life Insurance Companies in Poland During Integration with the European Financial System, Electronic Journal of Polish Agricultural Universities, Vol. 14

Mehari, D. and Aemiro, T. (2013). Firm specific factors that determine insurance companies' performance in Ethiopia. European Scientific Journal, vol.9, No.10 ISSN: 1857-7881 (Print) e-ISSN 1857-7431

Pervan, M., Curak, M. and Marijanovic, I. (2012). Dynamic Panel Analysis of Bosnia and Herzegovina Insurance Companies' Profitability. Recent Researches in Business and Economics, pp.158-163

Venkateswarlu, R. \& Bhishma Rao, G., S., S. (2016). Profitability Evaluation and Ranking of Indian Non-Life Insurance Firms using GRA and TOPSIS, Journal of Insurance and Financial Management, Vol. 2, pp. 59-89 